\title{
Dorsal and neural expression of a tyrosine kinase-related Drosophila gene during embryonic development
}

\author{
Jochen Haller, Serge Côté, ${ }^{1}$ Günter Brönner, and Herbert Jäckle \\ Max-Planck-Institut für Entwicklungsbiologie, Abt. Biochemie, D-74 Tübingen, FRG
}

\begin{abstract}
Sequence analysis of an embryonic transcript of Drosophila predicts a tyrosine protein kinase-related gene. The prediction is based on several protein domains that are homologous to the functional domains of kinase-related oncogenes and several serine, threonine, and tyrosine protein kinases. For this reason, we named this gene Drosophila tyrosine kinase related $(d T K R)$. $d T K R$ maps into chromosome band $2 \mathrm{R}$ 60F1. It is intially expressed at blastoderm stage, showing transient transcript accumulations at dorso-lateral positions of the embryo and differences along its longitudinal axis. At later stages of embryogenesis, $d T K R$ transcripts are found exclusively in neural anlagen. Both the region-specific pattern of expression and the putative kinase function are consistent with the suggestion of a regulatory role for this gene during development, which remains to be elucidated.
\end{abstract}

[Key Words: Drosophila melanogaster; in situ hybridization; sequence analysis; transcript pattern; tyrosine kinase-related]

Received July 1, 1987; revised version accepted July 31, 1987.

During the past years, genetic and molecular analysis of Drosophila development has identified a number of genes that are active only in a subset of cells or tissues (for review, see Gehring and Hiromi 1986; Scott and O'Farrell 1986). The spatial and temporal patterns of expression of several of these genes have been revealed by in situ hybridization of molecular probes to tissue sections (for review, see Hafen et al. 1983; Scott and O'Farrell 1986). Aside from confirming the spatial patterns of expression of genes for which the domains of action are already characterized by mutant phenotypes, in situ hybridization allows identification of genes that are expressed in a limited number of cells or tissues, but for which no mutant phenotype has yet been identified. The value of this approach has recently been demonstrated with the caudal gene. It was first identified on the basis of an exciting pattern of transcript accumulation: a gradient along the longitudinal axis of the developing embryo (Mlodzik et al. 1986). Genetic analysis then proved that the caudal gene provides positional information for the developing embryo, as deduced from both the graded distribution of the protein along the longitudinal axis of the embryo and from the phenotype of caudal mutant embryos (Macdonald and Struhl 1986).

Analysis of the chromosome region 60 E9-F1 at the tip of the right arm of the second Drosophila chromosome revealed five transcripts that are expressed during early embryogenesis (Côté et al. 1987). One of them, arbitrarily termed "g2", maps into the $60 \mathrm{~F} 1$ chromosome band. This anonymous gene is first expressed as early as blastoderm stage (Côté et al. 1987). Here we report its

'Present address: Ontogénèse et Génétique Moléculaires, CHUL, Quebec, Canada. temporal and spatial patterns of expression during embryogenesis. Sequence comparison with protein kinases reveals conserved motifs found in tyrosine kinase. Thus, we named this gene Drosophila tyrosine kinase related $(d T K R)$.

Results

Changes of the spatial and temporal patterns of $\mathrm{dTKR}$ gene expression

Initial expression of the $d T K R$ gene occurs at blastoderm stage (Fig. 1). As described recently (Côté et al. 1987), this expression is restricted to the dorsal and lateral region of the embryo. During the blastoderm stage (stage 14; Foe and Alberts 1983|. dTKR transcripts decrease in the anterior and posterior-most region of the embryo, and they gradually disappear from lateral to dorsal (Fig. 1a-d). At the end of blastoderm stage, the transcripts are restricted to the dorsal region of the embryo covering about $20-85 \%$ of the egg length (posterior pole is $0 \%$ ). Within this domain of expression, transcripts accumulate unevenly. Between $20 \%$ and $50 \%$, rather low levels of $d T K R$ transcripts can be detected. They rise to high levels between $50 \%$ and $85 \%$ egg length, forming a wedge-shaped stripe on the dorsal surface (Fig. 1e,f).

During gastrulation, $d T K R$ transcripts accumulate in the dorsal region of the cephalic furrow and cover the procephalic neurogenic ectoderm /Campos-Ortega and Hartenstein 1985/. During the extended germ band stage, transcripts begin to disappear gradually from the procephalic neurogenic region toward posterior. They remain last in the amnion serosa (Fig. $2 \mathrm{a}-\mathrm{c}$ ). When parasegmental furrows appear prior to germ band retraction 

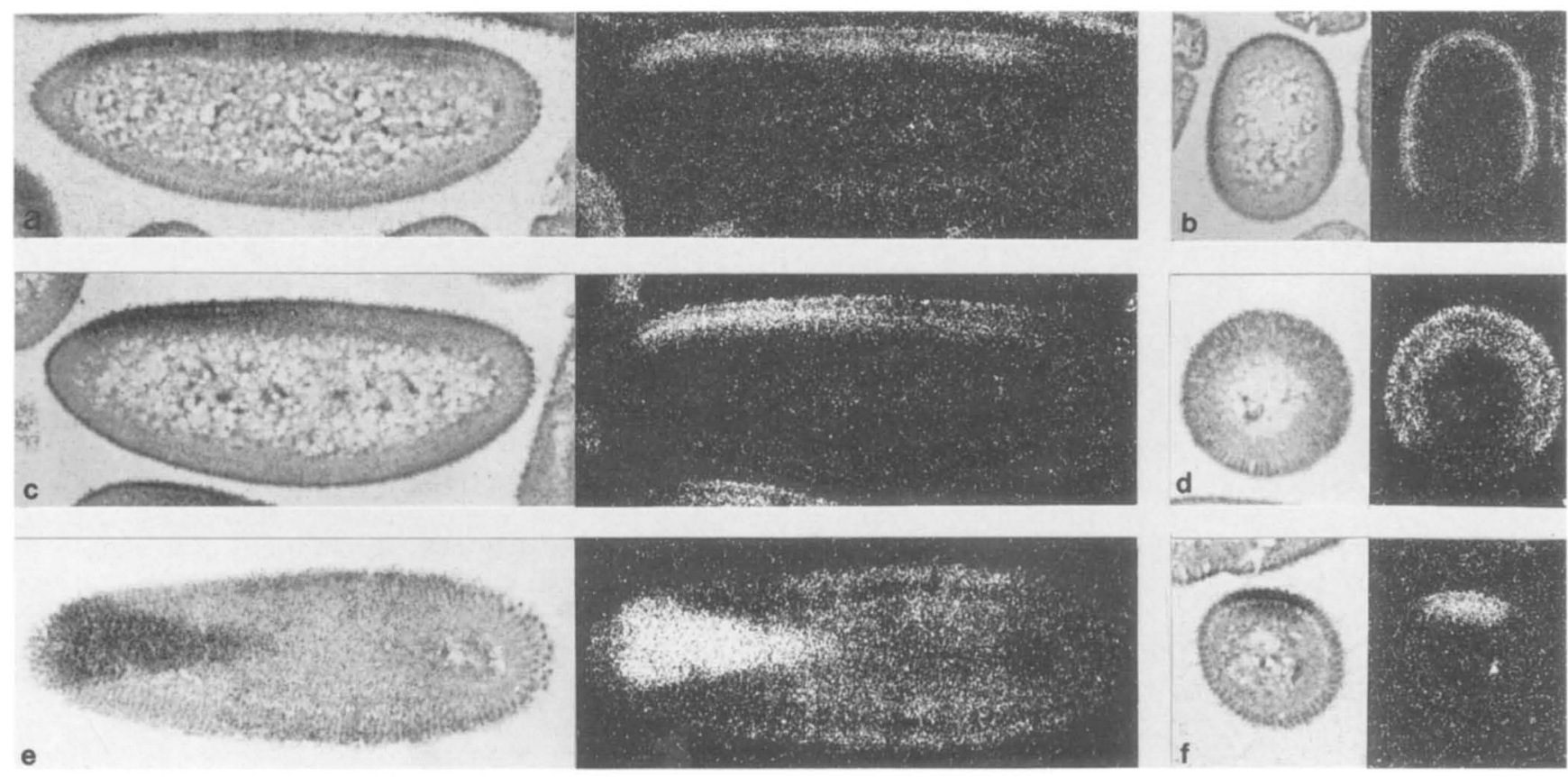

Figure 1. Spatial and temporal patterns of $d T K R$ transcripts during blastoderm stage. Sections of blastoderm stage embryos were hybridized in situ using the $d T K R$ cDNA probe. Orientation of embryos is anterior left $(a, c, e)$, dorsal uppermost $(a-d, f)$. Photomicrographs (left) and corresponding dark-field images (right) are shown. (a) Sagittal section of an early-stage 14 embryo (Foe and Alberts 1983). Transcripts accumulate between $20 \%$ and $85 \%$ of the egg length (posterior pole is $0 \%$ ). Note the absence of transcripts at the ventral region as can be seen in the cross section of an embryo at the same stage shown in $(b)$. During stage 14, transcripts become restricted to the dorsal site (see cross sections $d, f$ ) and accumulate more heavily in the $50-85 \%$ region of the embryo (see parasagittal section $c$ ). At late-stage 14, transcripts show a wedge shape accumulation pattern of high intensity in the dorsal region (dorsal-horizontal, tangental section in $e$ ) and low levels of transcripts posterior to $50 \%$ egg length.

(Martinez-Arias and Lawrence 1985), transcripts disappear from the dorsal position (Fig. 2d), and new $d T K R$ expression was observed in the developing nervous system. From then on, the transcripts remain in the developing nervous system, including the brain (Fig. 2e,f), until they disappear completely at the end of embryogenesis. Based on Northern blot analysis, major $d T K R$ expression is unlikely to occur at later stages of the Drosophila life cycle (Côté et al. 1987).

\section{Structure and function of dTKR}

Several cDNA clones were isolated from a library prepared from poly $(\mathrm{A})^{+}$RNA of 3- to 12 hr-old embryos as decribed in Côté et al. (1987). The longest cDNA clone was used to map most of the $d T K R$ transcript to genomic DNA (Fig. 3a). It extends over more than $8 \mathrm{~kb}$ of genomic DNA, suggesting several introns. To analyze the $d T K R$ gene structure and possibly to reveal the biochemical function of the $d T K R$ gene product, we sequenced the cDNA clone, the corresponding genomic DNA, and the genomic DNA upstream of the 5' end of the cDNA clone.

Most of the $d T K R$ transcript was recovered in a cDNA clone which, however, is close to full size (see below and Fig. 3b). The transcription and translation initiation sites are not unambigously identified. However, likely candidates for a CAAT and the TATA box as well as the presumptive translation start site were detected in the genomic DNA upstream from the $5^{\prime}$ end of the cDNA clone (Fig. 3b). A single open reading frame extends from the first ATG codon to position 2259 (Fig. 3b), which would encode a 753-amino-acid polypeptide (see below). The open reading frame is constructed from three exons: a $5^{\prime}$ exon of $1357 \mathrm{bp}$ followed by a small 132-bp exon and by a 1895-bp $3^{\prime}$ exon. They are separated by two introns of about 2.5 and $3.8 \mathrm{~kb}$, respectively (Fig. $3 \mathrm{~b}, \mathrm{c}$ ). The $3^{\prime}$ region of the cDNA contains a single polyadenylation signal (AATAAA) followed by two such signals in genomic DNA. This suggests that the first polyadenylation signal is the one being used at least in the transcript represented by the cDNA that we sequenced (Fig. $3 \mathrm{~b}$ ). From these data, differential termination, initiation, and additional splicing cannot be excluded, although Northern blot analysis revealed only a single major transcript, the size of which would be consistent with the length of the transcript of about $4 \mathrm{~kb}$ (Côté et al. 1987).

The $d T K R$ sequence predicts a 753-amino-acid polypeptide with putative protein kinase function. We observed two portions of the $d T K R$ protein that are weakly homologous to the protein kinase domain of the avian ves oncogene (Fig. 4); one is conserved in other avian oncogenes as well as in several homologous serine, threonine, and tyrosine kinases (Fig. 4b,c). The degree of homology with these known kinases is low, but it suggests that $d T K R$ may encode a protein kinase. Further evidence for this suggestion comes from the notion of 


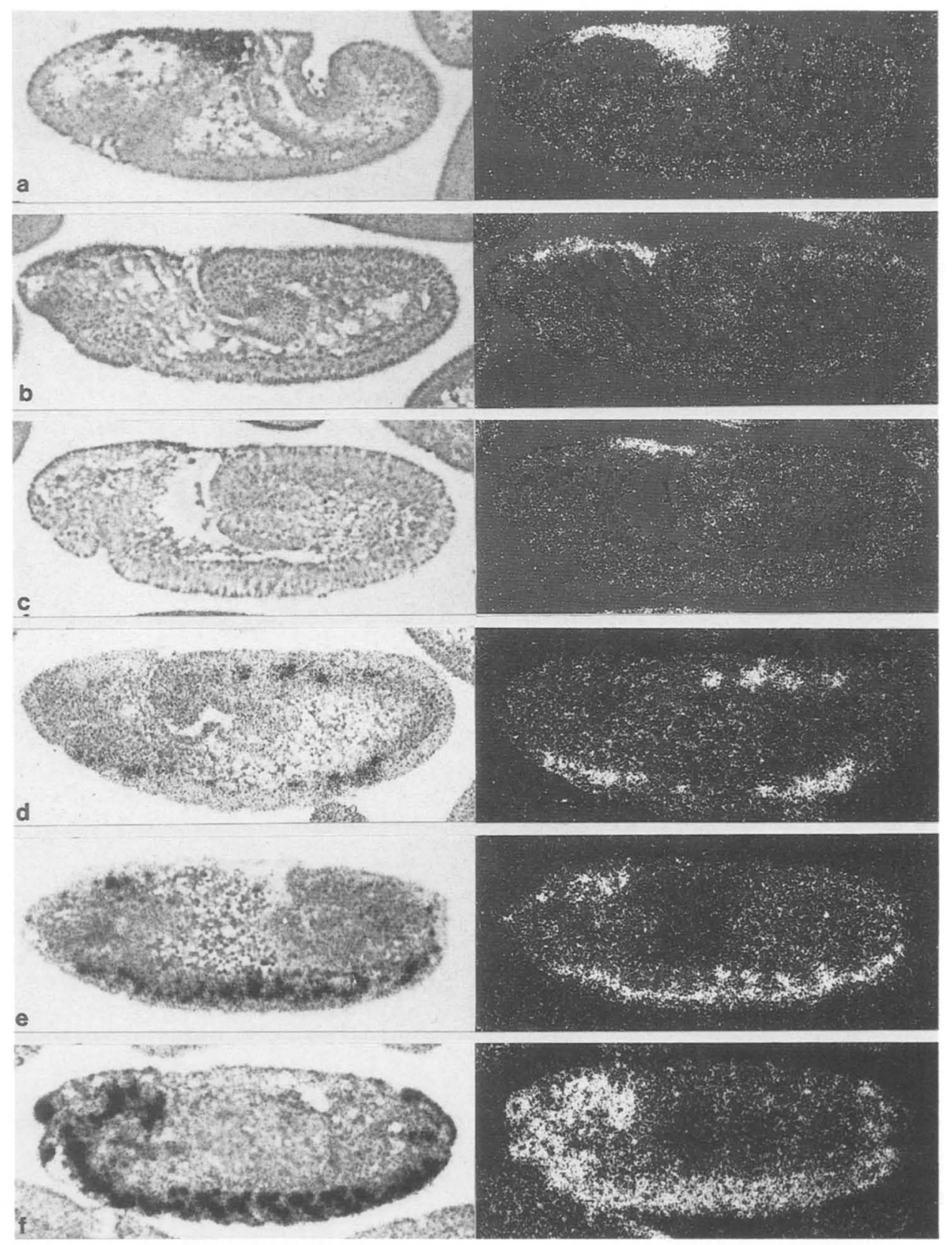

Figure 2. Patterns of $d T K R$ transcripts during gastrulation and neurogenesis. Parasagittal sections through embryos are oriented anterior left and dorsal uppermost; (left) photomicrographs; (right) dark-field images. (a) Early gastrulation. Labeling appears in the amnion-serosa precursors extending into the procephalic neurogenic region. $\langle b, c|$ Extended germ band stages. Note the accumulation of transcripts over amnion serosa cells. (d) Advanced extended germ band stage. Note transcripts appearing in the nervous system. $(e)$ Germ band retraction; $(f)$ Shortened germ band. Note that transcripts accumulate heavily in the ventral nervous system and brain.

Figure 3. Physical map and sequence of the $d T K R$ gene. $(a)$ Restriction map of $d T K R$ DNA (top) and $d T K R$ cDNA (below). For location and orientation of the genomic DNA in chromosome region 2R 60E9-Fl see Figs. 2 and 3c in Cote et al. (1987). Exons are indicated by black boxes in cDNA, transcription is right to left (indicated by arrow at the $3^{\prime}$ end). Restriction enzymes used were $A c c I$ (A), BamHI (B), HindIII (H), PstI (P), PVuII (I), SacI (S). (b) Nucleotide sequence and predicted amino acids of the $d T K R$ gene. Sequence of genomic DNA (light letters) and cDNA (heavy letters). A single base difference was found in the open reading frame (position 2156; $C$ in genomic DNA vs. $G$ in cDNA; position values for bases are given on the left side above the sequence), $(c)$ exon-intron boundaries. Three base pair differences were observed in the $3^{\prime}$ untranslated sequence in positions 2766,2797 , and 3039 as A,G,G in genomic DNA, respectively. The position of putative CAAT and TATA boxes as well as the polyadenylation signals are underlined. The amino acid sequence is given below the nucleotide sequence; positions are indicated at the right side. Amino acids encoding the consensus sequence of the putative ATP-binding site are printed dark, the putative autophosphorylation site is marked *. Putative glycosylation sites (Asn-X-Ser/Thr) are underlined, as is the direct repeat Lys-Glu-(Leu or Phe)-Gly-Lys-Glu-Phe-Gly. Note that this repeat contains a subrepeat Lys-Glu-(Leu or Phe)-Gly. See Fig. 4 for comparison with other kinases. 


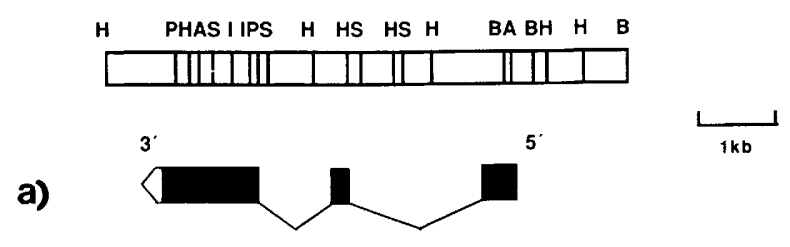

(b) - 150 TAAGACGACTGCAGTTTGCTATTTATACACTTATTATTGATTGTCACAGT (b) - 100 GAAAATCAATATTTAATAATAATTTTTTTGTCCACAGTGTTTCGTCTCG 1 -50 ACTCACCACTTCGACTCTTTCCACCCGGATCGATCCTGGCAAGCTTTTG ATGCCGTCCGCCCGACTGTTTGGCAACGC ITCAAGCCCCATTGCTGCTCTAGCTTTGCGA

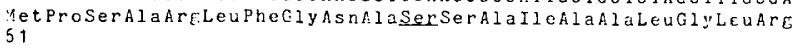

CGAAAACGAGAGCAGGAGTCCOACCGCGACTTGCAGAGTGATCAGGAGCTGCGAGGCAGT

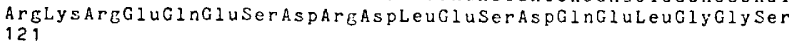
TCACC TATGCCACGACGTAAGCAAGCGCGACCGCGGCGCCGCTCCGGGCATCTGCCGCAC SerProliet ProArgArgLysGInAlaArEPrOArGArEArGSerGly HisVal ProHis SACT TTACC TTAAACAAAACCGATGCAGAATCCTTGCAAACTGTGATCAAGCACGAGCTT As p PheThrLeuAsnLy ShrAspAlagluSerLeuGinThrVal I eLysHisGluLeu
241

CTAGAGCGAGCGGAAAGAGATCAGGAAGAGGCTCCTGATCGAGATAACAGCCAAGGGGAA LeuGluArgAlaGluArGASpGInGIUGIUAlaProAspArEAsPASnSerGInGIyGIu 301

GCTGAAAAAATTAGTTCGTCGCCAGCAAAAACTTGGTTGAACGGGCTAAGGAGCAAAAG

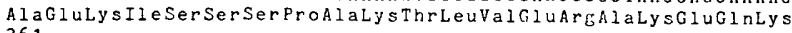
361

TCCATGAAACAAGAAGCATCCAATCAACCAAGCACTCTAAACGAGAATCACCATCAACTC SerHetLysGlnGluGly SerAsnglnProSerSerLeuAs nGluAsnHis HisClnLeu
421

GAGCTTGACCATGAGGACCACCACCATCAGGATCATGAAGAGGAAGAGGAGCAAGACATT GI ULEUASPASPGIUASPASPASPASPGInAsPHISGIUGIUGIUGIUGIUGInASPIIE
481

GAAGAGCTTATTCATACGACCAACCAGCTGAGGCGTCAGGCTGCAGCACCTGCTGCAAAT

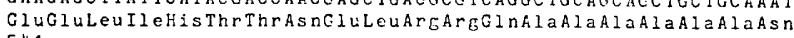

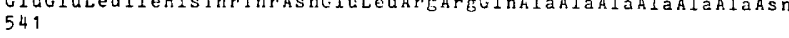
GCAGCCGCCATGTCTCCCAACCCTTCTCCCTGCCTCAGTGACGCGCCCGAGGACCTCTGC AlaAlaAlatiet SerProAsnProSexProCysLeuSerAspG y ProGluAspleuCy 601

ACCACTAACAAAGCCAAGGAACTAATTTCTGGCCCCTCTAGTTCGGCAGACTGTGAGTCC ThrThrLy SLy SG y L Y SG IuLeuIl ESerGi y ProSerSerSerAlaAspCysGluSer 661

AATAACAACAACAGCAGCAAGCTGCAGGACAACAACCAGCGCATAATGCTCTCTCTAAAO

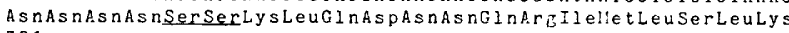
21

3ACATCCGCCAACTAAACGCTAATCCGAACCCTACGGCCATCCACACGCCTACTAGCTGT AspIl eArgGl nLeuAsnAIaAsnProAsnProThrAla I leHisThrProThrSerCys

TCTGGGGGCAACAACEGACTAC TTACTT TCCC TCCGCCCGGACTTCGGCCTCCTGGTCTA

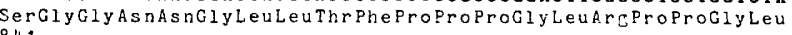

CCAGACAGCCCGCCC TGCCACATGGAAGCGC TAGAGGCACAGATGCACGCAGCTGCTGCT

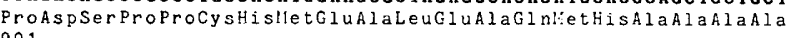
901

GCTGCCGTGGCGGCTGCTGGATC TGGGGAGCATCCCTTCCATCATATGGACCACCAGATG AlaAlaValAlaAlaAlaGly SerGlyGluHis PropheHisHis:letGluFisGlul!et 961

GAGATGTCTTTGGCGGCTGCAGCGGCAGCTGCTGCGATGCATCAGCGTGAGCCACGGGAT

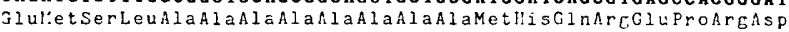
1021

CCCCGTGATGGGCGCGACCACAACGCATTTGCGAGCAATTTGCTGGGGCCAATGGGGTG

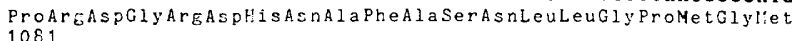
CCCCCGTTCGGAGGACATAACGGAGGCCATCCGGGCAACAGTGGTCCAGGAAACGGATGT ProproPheGlyGlyHis isnGlyGlyHisProGlyAsnSerGlyProGlyAsnglyCys 1141

CCTGGACAAGC TGCGCACGAAAGACTTGAGGAGAGTATGAATCGACTGAGTAAGGAGCTT

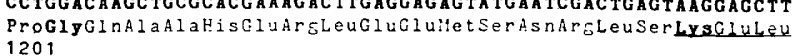
1201

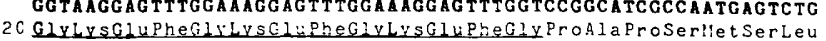

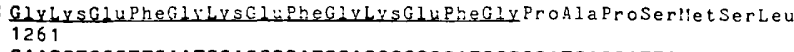

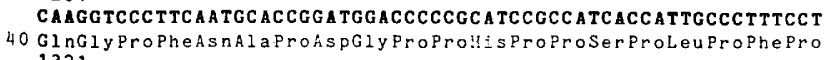
1321

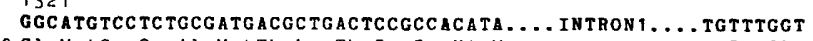

60 Gly MetSerSerAlahtet ThrLeuThrProprohisi: etPheGly 1366
CTCGACTCACCACTTGGACTCTTTCCACCCGGAATCGATCCTGGCAAGCTTTATAACCCG

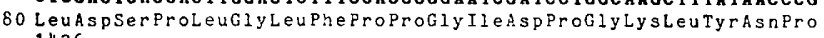
1426

TTAATGGAAATGAGCGATCCAAGGGACATGCCTGGCGGGCCGCCTCCATTCCTTAAAAG

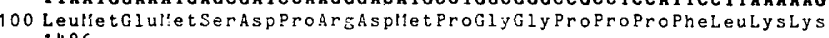
1486

AAAA.... INTRON2... TGCCGCGACCAAAGGGACAGCACTCAGCCCCACGCGGCGGT

120 LysM 1531 etProArgProLysGlyGI InFis SerAlaProArgGlyGly 1531 CCTCCACGCTCATGGACTAACACAGAACTGACGGAGGCACTGCAGCACGTTTGGAACAAA

140 ProproArs SerTrpthrasnThrGluLeuThrGluAlaLeuglnHisVal TrpAsnLys 1591

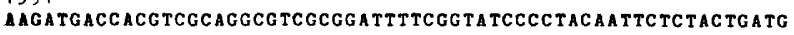
160 Lysl:etThrThrSerGlaAlaSerArgilePheGlyIleProTyrasnSerLeuleuliet
1651

Figure 3. (See facing page for legend.)
TACGTCCGGGGAAATACGGAAAGAGTTTAAAACTGGAGCAGC TGCGGAAGGCTGCATC

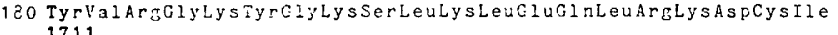
1711

AGTGGACCACCGATAGAAATGCTGCAAATGGGCATCGGCGGAGGTAGCGGTGGTTCCACG

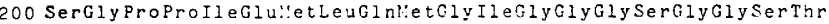
1771

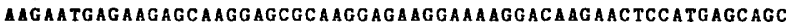
220 LysASnGIULYSSerLySGIUARELYSGIULYSGIULYSASPLySASnSerifetSerSer 1831

AACGGTTCGGGGGGTCTGCTAATTCCCAAGGCGGAGCACCGACC TCCGGCAGTGGACCA 240 AsnGly SerGlyGlySer Al a S SnSerGinglygly Ala ProThrSerGly SerGly Pro 180

ATGCAGCATTCCGGTGAACTGGGGCCTATGGGACAGTTAGACCTGGATCTGGGACTTCCC 260 MetGlnHis SerGI yGluLeuGly Proliet 1 y GlnLeuAspleuAs pLeuGlyLeuPro CTGGGACCCCCAGGAGGACCCCGTAGTAACAGTTCCGAGCCCGATTTAC TGAGTGCCCCA 280 LeuGIy ProProGiyGIy ProAr sSerAsnSerSerGluProAspLeuLeuSerAlaPro

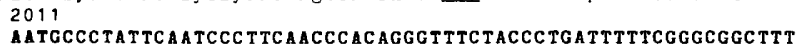
300 A SnAlaleuPheAsnProphefsnProGlngly fheTyrProfsp PheSerGlygly Phe 2071

CCCGGCCTCCC TCTGAGCATGTTAAACC T TTTGCCGCCGGCAGAACGCCATCATGCAGCT

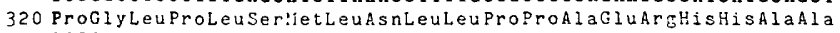
2131

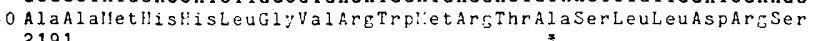
AGTCC TCTTCCGTGGACGAAGACTACTCAGG TCCTGGAATACCGC TCCCGCTGGAGCACC 360 SerProLeuProtroThrLys ThrThrGinVal LeLCIUTy

GTCGGGAGATAAGCGCGACGGGCCCACCACTTACCCCATCCAACGGTGGGACCGGGATG 380 ValGIYArC, 753

2311

ATTGAAATTGTGGCGGGATTGGGCAGCCGGGGCTGCCAACGCCAATCCAATGTACTTCC

14002371

C TGCTTTTGAGC TGGACCAGGAAATGACCCTACCCCGCCGTCCCTGCCTTCTCGACCCG 2431

420 CCCTTCACCAACTGGCTTGCCGTGAGCTCAGCTTTAAGCCAGACCTGTTCATGGCCAGA 2491

GAAAGCTGAAACGCTTTCGGGCCAAGCGTCAGCTCCAAGCGCAGATCGAGACGCCGACAG

41,02551 CAGCCGTTCCCGCTCCTTGTCCCGTAAGCAACGCGTTGCCACCGCTAAGACTTAAAGGA 2611

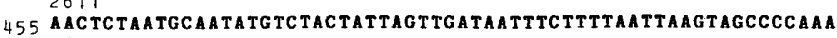
2671 GGAATACATTTTGTGAGGACTAGGTGTTTTTTTCTTIAAGTAATAATTTACTGGTGCTT 4752731 2791

495 A TAT AGG

5102931 CAAACTAACAAAAG TTTGGAGCAAGTTGAGGGAAACCCAATGCAATTATAAGTATCG 2991

530 AAGGATACAAAGCCGATGACTGTACCAAA ATTTTTATGTTATTTAACAATCAAATGAA 3051

550 3111

G111 GCACAAA 317 ?

570 GTTATTCCTAAATGCAGCTTTGTAAATCTCAGCAAATAATGGAACCCTGCAGATTTACCC 3231

5003291

3291

610 TAATATTTCAACAGAAACG TATGTAAGTGAATAAGTTAAACGTATACATTAAATAA

630 ATAGTACAAGTTATTAAATAAAACCTTTICTTTTATGAATAGTTTTCATAGG

650

670

(c) IITRON 1 CAT TGTTT 690

710 II!TRON: 2 AAA AAA TGCCGC 


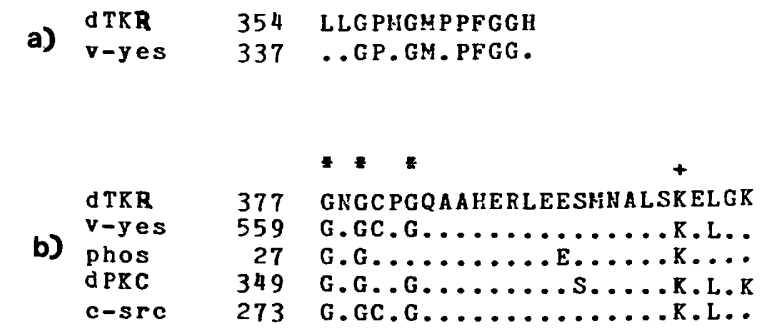

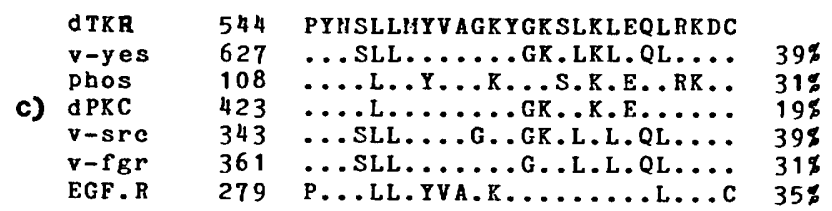

Figure 4. Homology between the $d T K R$ protein and other serine, threonine, and tyrosine kinases and related oncogenes. (a) Amino-terminal homology with the avian ves oncogene. $(b)$ Homology within the ATP-binding domain. (*) Gly-X-Gly-X-XGly motif; $(+)$ putative ATP-binding lysine residue. $(c)$ Conservation of amino acid residues within the catalytic kinase domain of several kinases and kinase-related oncogenes as described in detail by Hunter and Cooper (1985) and by Rosenthal et al. (1987) for the Drosophila protein kinase C homolog gene $(d P K C)$. Numbers and abbreviations refer to the positions of sequences within the different proteins as described in the above references. Corresponding amino acid residues in the different protein sequences are printed in the one-letter code, exchanged amino acids are indicated by dots. $(\%)$ Percent amino acid conservation.

strong candidates for both an ATP-binding lysine residue (Kamps et al. 1984) and a tyrosine autophosphorylation site (Hunter and Cooper 1985) within the $d T K R$ amino acid sequence (see below).

The presumptive ATP-binding lysine residue within the $d T K R$ sequence (position 398; Figs. $3 \mathrm{~b}, 4$ ) is preceded by the amino-terminal consensus sequence Gly-X-Gly$\mathrm{X}-\mathrm{X}-\mathrm{Gly}$, which is characteristic for an ATP-binding domain in protein kinases (Wierenga and Hol 1983). This lysine, however, is part of an eight-amino-acid direct repeat. Thus, ATP-binding to this second lysine (position 406) within this repeat or even the ATP-binding to both residues at the same time cannot be excluded. As observed with several tyrosine kinases, the carboxy-terminal tyrosine of the $d T K R$ sequence (position 744) contains a basic amino acid residue seven positions upstream of the tyrosine (Fig. 3b). This tyrosine is adjacent to an acidic amino acid; thus, it fulfills the criteria for representing the site of highest autophosphorylation in tyrosine kinases (reviewed in Hunter and Cooper 1985). The presence of putative sites for both ATP-binding and autophosphorylation suggests that the $d T K R$ gene product may have tyrosine kinase function. Hydropathy plots (Kyte and Doolittle 1982) with the $d T K R$ sequence did not show any evidence for a membrane-spanning domain. This may argue for $d T K R$ being a cellular rather than a membrane-associated tyrosine kinase; in this case, the putative glycosylation sites (Fig. 3) would not be glycosylated.

\section{Discussion}

We report the identification of a tyrosine kinase-related Drosophila gene that is active during early stages of embryonic development. The domains of $d T K R$ expression suggest specific and transient activity of this gene in a dorsal location and, later, in the developing nervous system. The conservation of an ATP-binding site and a tyrosine autophosphorylation site, as well as homology within the catalytic domains of several other protein $\mathrm{ki}$ nases, suggests a similar, if not identical, biochemical function for this gene as known for well-characterized tyrosine kinases (reviewed in Hunter and Cooper 1985), although the invariant sequence -His-Arg-Asp-Leu-XAla-X-Asn-X-Leu-Val- (located just downstream of the sequences shown in Fig. 4c) of all tyrosine kinases is absent from the $d T K R$ sequence.

Recently, the involvement of a specific tyrosine kinase activity in neuronal cell specification has been demonstrated with the Drosophila gene sevenless (sev). The sev protein product, a transmembrane receptor with a tyrosine kinase domain (Hafen et al. 1987), is essential for the development of a single class of photoreceptor cells in the compound eye (Tomlinson and Ready 1986; Banerjee et al. 1987). Furthermore, cell communication seems to be essential for developmental decisions within the "neurogenic region" of the Drosophila blastoderm stage embryo (for review, see Campos-Ortega and Hartenstein 1985). In the neurogenic region, cells of the same pool of precursors become committed to specify either neural or epidermal cells, which allows them to develop either the ventral nervous sytem or epidermis. This developmental decision involves the class of neurogenic genes (Lehmann et al. 1983). One of the neurogenic genes, Notch, encodes a transmembrane protein and epidermal growth factor (EGF)-repeat sequences (Wharton et al. 1985; Kidd et al. 1986). This finding is consistent with the genetic and molecular analysis favoring the argument that Notch (as well as several other neurogenic genes) participates in cell communication mediated by membrane-bound molecules. At least one other neurogenic gene contains EGF-like repeat sequences (Knust et al. 1987).

The transient and region-specific expression of $d T K R$ favors the argument that $d T K R$ has a regulatory function, as proposed for the other tyrosine kinases. This function may be, for example, phosphorylation of cellular proteins or receptors to modulate the activities of neurogenic gene products. This proposal for $d T K R$ function is supported by the striking resemblance of the spatial patterns of expression of $d T K R$ to a candidate for crumbs $(c r b)$, a putative neurogenic gene of Drosophila that contains EGF-like repeats (see above; Knust et al. 1987).

As part of the effort to understand the role of tyrosine kinases and in particular the role of cellular oncogenes containing tyrosine kinase domains, a number of Drosophila genes homologous to vertebrate oncogenes or hormone receptors have been isolated, including c-src, the EGF and insulin receptors (reviewed in Shilo 1987), and the protein kinase $\mathrm{C}$ homolog (Rosenthal et al. 1987). No 
mutants have been reported for any of these genes. For $d T K R$, we obtained chromosome deficiencies that uncover at least two genes in addition to $d T K R$ (Côté et al. 1987). Thus, the biological function of $d T K R$ cannot be analyzed unambiguously in those mutants. On the other hand, our molecular analysis supports the suggestion of a regulatory function for $d T K R$. This encourages further examination of the $d T K R$ developmental pathway involving screens for additional $d T K R$ mutations, interaction analysis with neurogenic genes, and the identification of the substrate for phosphorylation by $d T K R$.

\section{Materials and methods}

\section{DNA procedures}

DNA preparation of phages and plasmids, nick-translations to prepare ${ }^{32} \mathrm{P}$-labeled DNA fragments, and restriction map analysis were done as described in Schuh et al. (1986). Single-strand probes for in situ hybridization experiments were prepared from T3/T7 constructs as described by Côté et al. (1987) using $\left[{ }^{35} \mathrm{~S}\right] \mathrm{UTP}$ (Amersham).

\section{In situ hybridization of embryo sections}

In situ hybridization of molecular probes to tissue sections of embryos was carried out as described by Cote et al. (1987). Briefly, single-strand ${ }^{35}$ S-labeled RNA probes were used on tissue sections of paraffin-embedded embryos. The specific activity of the probes used was above $10^{7} \mathrm{cpm} / \mu \mathrm{g}$, and the average size was smaller than $200 \mathrm{bp}$.

\section{Sequencing}

Both cDNA and genomic DNA fragments were sequenced from single-strand phage subclones by the dideoxy chain termination method of Sanger as described previously (Schuh et al. 1986). For the data presented in Figure 3, the coding sequences were sequenced in both orientations in several subclones.

\section{Acknowledgments}

We would like to thank our colleagues in the lab for many stimulating discussions, and Dr. S.M. Cohen for critically reading the manuscript. S.C. was supported by a NSERC of Canada postdoctoral fellowship. Part of the work was supported by a DFG grant (Leibniz-Programm).

\section{REFERENCES}

Baneriee, U., P.J. Renfranz, J.A. Pollack, and S. Benzer. 1987. Molecular characterization and expression of sevenless, a gene involved in neuronal pattern formation in the Drosophila eye. Cell 49: 281-291.

Campos-Ortega, J. and V. Hartenstein. 1985. The embryonic development of Drosophila melanogaster. Springer Verlag, Berlin, Heidelberg.

Côté, S., A. Preiss, J. Haller, R. Schuh, A. Kienlin, E. Seifert, and H. Jackle. 1987. The gooseberry-zipper region of Drosophila: Five genes encode different spatially restricted transcripts in the embryo. $E M B O J$. (in press).

Foe, V.E. and B.M. Alberts. 1983. Studies of the nuclear and cytoplasmic behaviour during the five mitotic cycles that precede gastrulation in Drosophila embryogenesis. I. Cell. Sci. 61: 31-70.
Gehring, W.J. and Y. Hiromi. 1986. Homeotic genes and the homeobox. Annu. Rev. Genet. 20: 147-173.

Hafen, E., M. Levine, R.L. Garber, and W.J. Gehring. 1983. An improved in situ hybridization method for the detection of cellular RNAs in Drosophila tissue sections and its application for localizing transcripts of the homeotic Antennapedia gene complex. EMBO /. 2: 617-623.

Hafen, E., K. Basler, J.-E. Edström, and G.M. Rubin. 1987. sevenless, a cell-specific homeotic gene of Drosophila, encodes a putative transmembrane receptor with a tyrosine kinase domain. Science 236: 55-63.

Hunter, T. and J.A. Cooper. 1985. Protein-tyrosine kinases. Annu. Rev. Biochem. 54: 897-930.

Kamps, M.P., S.S. Taylor, and B.M. Sefton. 1984. Direct evidence that oncogenic tyrosine kinases and cyclic AMP-dependent protein-kinases have homologous ATP-binding sites. Nature 310: $589-592$.

Kidd, S., M.F. Kelley, and M.W. Young. 1986. Mol. Cell. Biol. 6: 3094-3108.

Knust, E., U. Dietrich, U. Tepass, K.A. Bremer, D. Weigel, H. Vässin, and J.A. Campos-Ortega. 1987. EGF homologous sequences encoded in the genome of Drosophila melanogaster, and their relation to neurogenic genes. EMBO $J$. 6: $761-766$.

Kyte, J. and R.F. Doolittle. 1982. Evaluation of protein hydropathy. I. Mol. Biol. 157: 105-132.

Lehmann, R., F. Jimenez, U. Dietrich, and J. Campos-Ortega. 1983. On the phenotype and development of mutants of early neurogenesis in Drosophila melanogaster. Wilhelm Roux's Arch. Dev. Biol. 192: 62-74.

Macdonald, P.M. and G. Struhl. 1986. A molecular gradient in early Drosophila embryos and its role in specifying the body pattern. Nature 324: 537-545.

Martinez-Arias, A. and P. Lawrence. 1985. Parasegments and compartments in the Drosophila embryo. Nature 313: 639642.

Mlodzik, M., A. Fjose, and W.J. Gehring. 1986. Isolation of caudal, a Drosophila homeo-box containing gene with maternal expression, whose transcripts form a concentration gradient at the preblastoderm stage. EMBO I. 4: 2961-2969.

Rosenthal, A., L. Rhee, R. Yadegari, R. Paro, A. Ullrich, and D.V. Goeddel. 1987. Structure and nucleotide sequence of a Drosophila melanogaster protein kinase C gene. EMBO $\mathrm{F}$. 6: 433-441.

Schuh, R., W. Aicher, U. Gaul, S. Cote, A. Preiss, D. Maier, E. Seifert, U. Nauber, C. Schröder, R. Kemmler, and H. Jäckle. 1986. A conserved family of nuclear proteins controlling structural elements of the finger protein encoded by Krüppel, a Drosophila segmentation gene. Cell 47: 10251032.

Scott, M.P. and P.H. O'Farrell. 1986. Spatial programming of gene expression in early Drosophila embryogenesis. Annu. Rev. Cell. Biol. 2: 49-80.

Shilo, B.-Z. 1987. Proto-oncogenes in Drosophila melanogaster. TIG 3: 69-72.

Tomlinson, A. and D.F. Ready. 1986. sevenless, a cell-specific homeotic mutant of the Drosophila eye. Science 231: 400402.

Wharton, K.A., K.M. Johansen, T. Xu, and S. Artavanis-Tsakonas. 1985. Nucleotide sequence from the neurogenic locus Notch implies a gene product that shares homology with proteins containing EGF-repeats. Cell 43: 567-581.

Wierenga, R.K. and W.G.J. Hol. 1983. Predicted nucleotidebinding properties of $\mathrm{p} 21$ protein and its cancer-associated variant. Nature 302: $842-844$. 


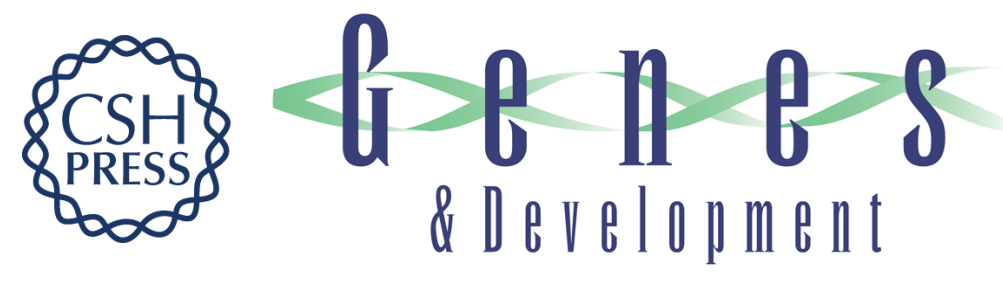

\section{Dorsal and neural expression of a tyrosine kinase-related Drosophila gene during embryonic development.}

J Haller, S Côté, G Brönner, et al.

Genes Dev. 1987, 1:

Access the most recent version at doi:10.1101/gad.1.8.862

References This article cites 21 articles, 4 of which can be accessed free at: http://genesdev.cshlp.org/content/1/8/862.full.html\#ref-list-1

License

Email Alerting

Receive free email alerts when new articles cite this article - sign up in the box at the top Service right corner of the article or click here.

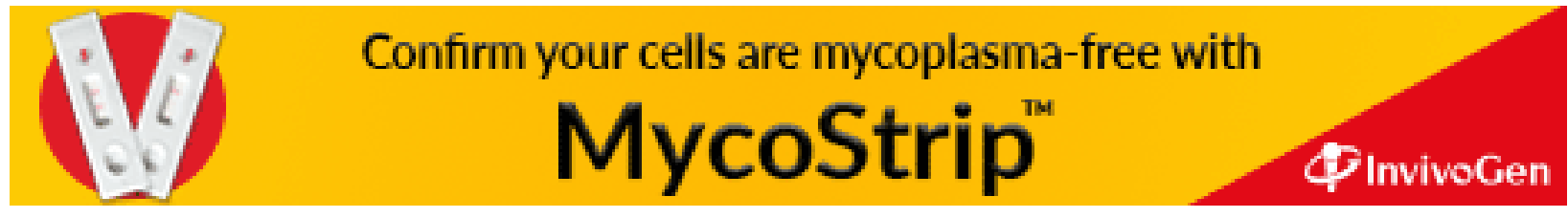

